\title{
Vehicle Front Structure Energy Absorbing Optimization in Frontal Impact
}

\author{
Hao Chen", Yali Yang and Liangjie Wang \\ College of Automotive Engineering, Shanghai University of Engineering Science, Shanghai, 201620, China
}

\begin{abstract}
Energy absorption performance is one of the most important indexes in the vehicle safety during impact. Research on the car frontal structure energy performance and structure optimization was conducted in this paper. Whole vehicle model was established by HyperMesh and simulated in LS-DYNA. Simulation results indicated that modification was needed for the original structure to meet the industry requirements. Based on simplified whole vehicle model, orthogonal design optimization was implemented, including bumper cross beam material (A), bumper cross beam thickness (B), energy absorber groove distance (C), and front longitudinal beam groove number (D), with 3 levels for each factor. The best option was $\mathrm{B} 3 \mathrm{D} 1 \mathrm{~A} 3 \mathrm{C} 3$ which was gained by using range analysis and integrated balance method. Simulation results showed that both front and total energy absorptions were improved. The optimized structure increased front energy absorption to $51.1 \%$, which can meet the industry requirement.
\end{abstract}

Keywords: Energy absorbing, Front structure, Optimization, Orthogonal design, Model establishment, Model verification.

\section{INTRODUCTION}

In the field of automotive engineering, safety, energy conservation, environmental protection is considered to be the three main themes for the future of automotive industry development. With the increase of vehicle volume, more and more attention has been put on traffic safety, and the vehicle collision accidents are inevitable in the current scientific level. Furthermore, with the increasingly fierce competition in the national automobile makers, traffic safety has become a focus for many research institutes [1,2].

Among the crash patterns, frontal impact is the most common one, which accounts for about $40 \%$ of all crash accidents [3]. Most of the automobile frames are nowadays commonly designed with thin-walled structure, which can absorb energy through deformation in the collision process. In frontal impact, the front portion of car body is the main energy absorbing area. The more the energy is absorbed, the safer the occupant is. The main energy absorbing parts are the thin-wall parts, bumper, frontal longitudinal beam, engine hood and so on [4-6].

Research on the front structure and energy absorption performance during impact was focused on using precision model and algorithm. Zhang et al. (2007) [7] presented a new genetic algorithm based on stepwise regression method for multi-objective optimization for car crash. Wang et al. (2010) [8] studied the effect of material strain rate on vehicle acceleration and energy absorption. Cheng et al. (2011) [9] optimized front bumper to improve energy absorption performance of passenger car. Zhou et al. (2009) [10]

\footnotetext{
*Address correspondence to this author at the College of Automotive Engineering, Shanghai University of Engineering Science, No. 333 Longteng Road, Shanghai, Postcard: 201620, China; Tel: 86 13585901312; E-mail: pschenhao@163.com
}

conducted orthogonal optimization on front portion part thickness for energy absorption improvement. Wang et al. (2013) [11] studied the effect of thin-walled straight beam structure on the energy absorption performance by using FE method.

Energy absorption performance is one of the most important indexes in the vehicle safety during impact. Research on the car frontal structure energy performance and structure optimization was conducted in this paper, by HyperMesh and LS-DYNA software. And orthogonal design optimization was implemented to determine best structure for high performance on energy absorption.

\section{MODELS}

\subsection{Model Establishment}

The body CAD model was established by CATIA software. The CAD model was transferred into HyperMesh software for geometry healing and meshing. The final whole vehicle model was shown in Fig. (1). The car consists of 666 parts. The total mass was $1580 \mathrm{~kg}$. The total element was 908702 with 870742 nodes.

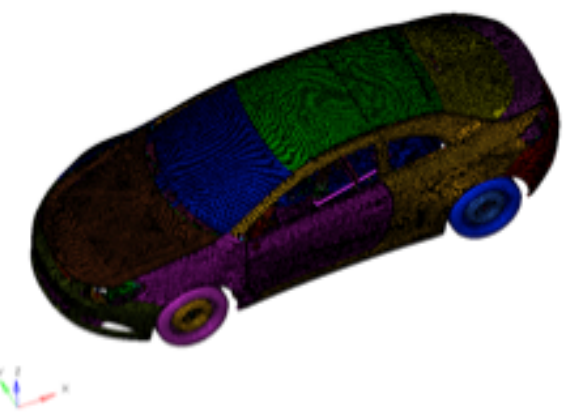

Fig. (1). Whole vehicle model. 


\subsection{Model Verification}

According to CNCAP regulation [12], vehicle initial $\mathrm{X}$ direction velocity should be $50 \mathrm{~km} / \mathrm{h}$ for $100 \%$ frontal impact with rigid wall. The impact time was $80 \mathrm{~ms}$. Impact simulation was conducted in LS-DYNA.

The energy curve during impact was shown in Fig. (2). The total energy curve was constant, which was consistent with the law of energy conservation. The hourglass energy accounted for to $2.94 \%$ of the total energy, which was lower than the industry rated value of $3.0 \%$. It was indicated that the simulation result was valid for impact analysis.

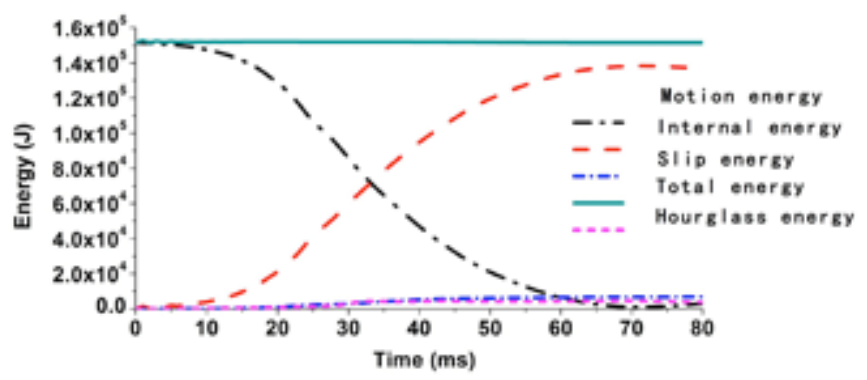

Fig. (2). Energy curve during impact.

\section{ENERGY ABSORPTION PERFORMANCE}

To understand the energy absorption feature, the whole vehicle model was simulated for $100 \%$ frontal impact. Table 1 shows the energy absorption for parts in the front portion of car. The energy absorption was concentrated in the front portion. Bumper cross member, energy absorption box, longitudinal beam, and sub-frame assemble were the main energy absorbing parts, which accounted for $49.78 \%$ of the total vehicle energy absorption. This value was lower than the regulation requirement of 50\% [13]. Thus, modification

Table 1. Energy absorption in the whole vehicle model.

\begin{tabular}{|c|c|c|}
\hline Part & Energy/J & Percent $/ \%$ \\
\hline Bumper cover & 6407.4 & $4.63 \%$ \\
\hline Radiator & 3915.4 & $2.83 \%$ \\
\hline Bumper cross beam & 7227.62 & $5.23 \%$ \\
\hline Energy absorber & 8782.24 & $6.35 \%$ \\
\hline Front longitudinal beam & 25508.3 & $18.45 \%$ \\
\hline Hood & 5031.18 & $3.64 \%$ \\
\hline Front wall & 3467.41 & $2.51 \%$ \\
\hline Fender & 660.75 & $0.48 \%$ \\
\hline Power train & 16.01 & $0.01 \%$ \\
\hline Sub-frame & 27307.96 & $19.75 \%$ \\
\hline Guard plate & 1433.97 & $1.04 \%$ \\
\hline Door & 164.64 & $0.12 \%$ \\
\hline Floor & 7589.47 & $5.49 \%$ \\
\hline Steering system & 2394.560 & $1.73 \%$ \\
\hline
\end{tabular}

should be done in the frontal portion to improve energy absorption performance, and to enhance cab safety.

B column Acceleration was another effective parameter to evaluate vehicle deceleration during impact. The $\mathrm{B}$ column acceleration was shown in Fig. (3). Imaginary line represent left side, and dot-dash line represent right side. The full line was the equivalent dual-trapezoids curve. The deceleration curve was relatively smooth, with maximum value of $34.2 \mathrm{~g}$, which can be further reduced.

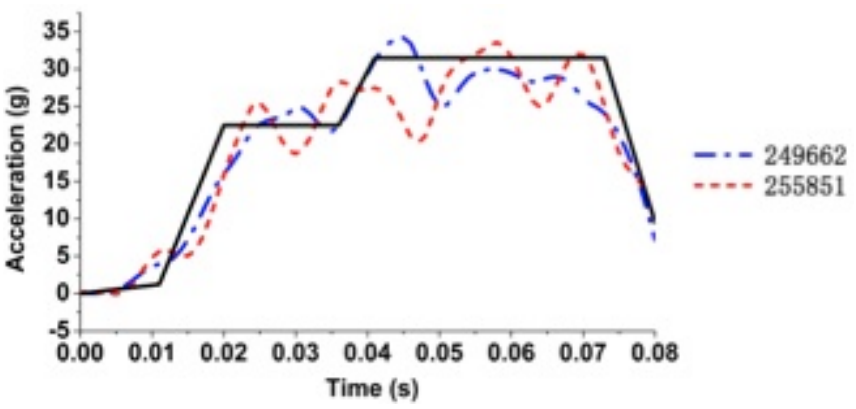

Fig. (3). B column acceleration during impact.

\section{FRONTAL STRUCTURE ORTHOGONAL OPTIMIZATION}

\subsection{Model simplifying}

During orthogonal design, enormous calculation should be done if using whole vehicle model. To improve simulation efficiency, the simplified model was used.

During impact, the front portion was the main energy absorbing area, accounting for more than $85 \%$ (Table 1). Little deformation was observed after B column. The structure after column B can be replaced by using mass point, which was connected with side wall and floor with rbe2 rigid element. The mass point shared the same coordinates with the original model. The simplified model is shown in Fig. (4).

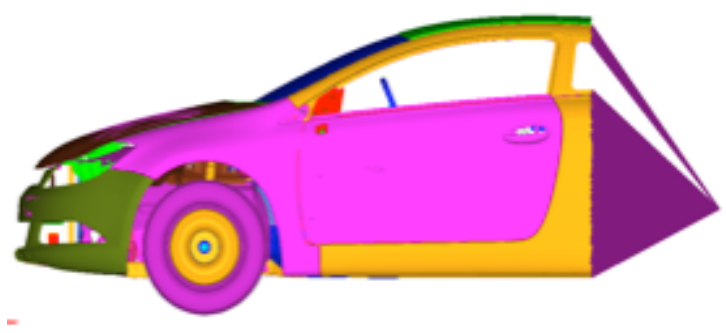

Fig. (4). Simplified vehicle model.

The simplified model was analyzed to verify its validation. Figs. $(\mathbf{5}, \mathbf{6})$ show the total energy and B column acceleration curve compared with original whole vehicle model.

The simplified model had almost the same amount of energy absorption (134786 J), i.e. only $1.6 \%$ lower than the original model. The same trend was observed in B column acceleration. The differences of maximum value between simplified and original models were lower than $3 \%$. Thus, the mass element can be used to represent the nondeformation area, to conduct high efficiency impact analysis. 


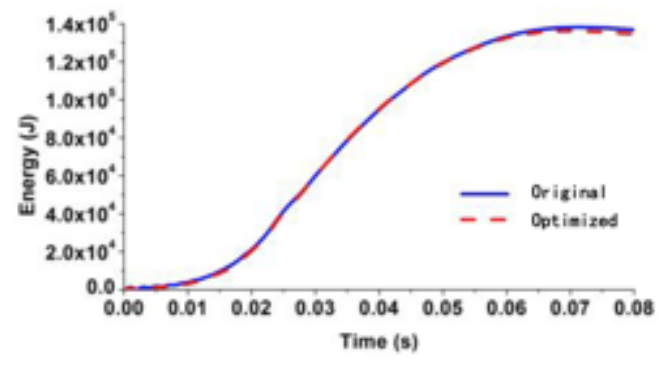

Fig. (5). Energy curve for original and simplified models.

\subsection{Orthogonal Optimization}

The main optimizing target was to increase front portion energy absorption, and reduce B column acceleration peak value. Thus, four factors were included, which are bumper cross beam material (yield strength (SIGY)), bumper cross beam thickness (inner and outer), energy absorber groove distance, and front longitudinal beam groove number. Each factor had 3 levels, shown in Table 2.

Table 2. Orthogonal design factors and levels.

\begin{tabular}{|c|c|c|c|c|}
\hline \multicolumn{2}{|c|}{ Factor } & Level 1 & Level 2 & Level 3 \\
\hline \hline A & SIGY /MPa & 240 & 358 & 587 \\
\hline B & Thickness/mm & $1.0 / 1.5$ & $1.2 / 1.8$ & $2.0 / 2.5$ \\
\hline C & Groove distance/mm & 0 & 25 & 45 \\
\hline D & Groove number & 1 & 2 & 3 \\
\hline
\end{tabular}

The orthogonal experiment table is shown in Table 3. For different combination, front energy absorption and B column acceleration peak value was used for impact simulation analysis.

To determine the best option, range analysis was used. Mean value $\mathrm{K}$ and range value $\mathrm{R}$ were calculated, as shown in Tables $\mathbf{4}$ and $\mathbf{5}$.

For energy absorption, the factor sequence from high to low were thickness (B), groove number (D), SIGY (A) and groove distance (D). Factor $\mathrm{B}$ and $\mathrm{D}$ had higher effect. Energy absorption increased with $\mathrm{A}$ and $\mathrm{B}$, and decreased with D. Thus, the best option for energy absorption was B3D1A3C2.

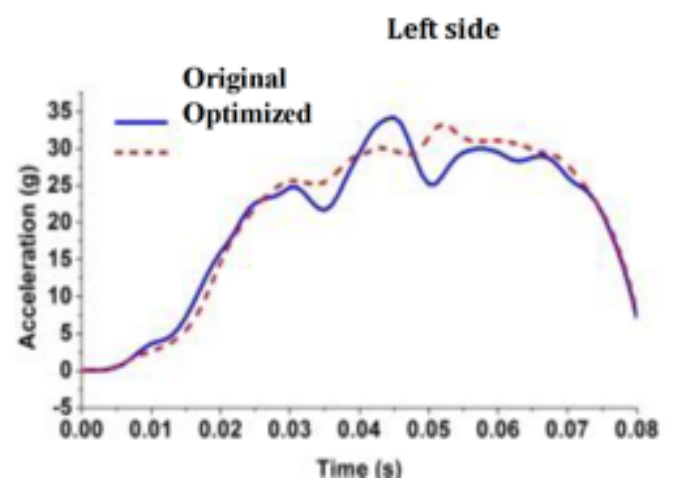

Fig. (6). B column acceleration for original and simplified models.
Table 3. $\quad \mathrm{L}_{9}\left(3^{4}\right)$ orthogonal design and results.

\begin{tabular}{|c|c|c|}
\hline Experiment & $\begin{array}{c}\text { Front Energy } \\
\text { Absorption (J) }\end{array}$ & $\begin{array}{c}\text { B Column Acceleration } \\
\text { Peak Value (g) }\end{array}$ \\
\hline \hline A1B1C1D1 & 66980.39 & 33.2317 \\
\hline A1B2C2D2 & 67198.70 & 32.0527 \\
\hline A1B3C3D3 & 67692.48 & 31.532 \\
\hline A2B1C3D1 & 66877.18 & 33.9209 \\
\hline A2B2C3D1 & 68316.26 & 32.5389 \\
\hline A2B3C1D2 & 68820.89 & 31.5258 \\
\hline A3B1C3D2 & 66878.51 & 31.3263 \\
\hline A3B2C1D3 & 66687.63 & 31.7574 \\
\hline A3B3C2D1 & 70665.78 & 33.128 \\
\hline
\end{tabular}

For B column acceleration peak value, the sequence was D-C-B-A. And the best option was D2C3B3A3.

As a multi-objective optimization, integrated balance method was used for the final optimization choice. As the main target was energy absorption, the factor sequence should be B-D-A-C. Based on the value and range, the optimization option was B3D1A3C3.

\subsection{Performance of Optimized Structure on Energy Absorption}

Modification was done according to the best option B3D1A3C3. Then, simulation was conducted in LS-DYNA, to compare its performance with original model, as shown in Table 6.

Compared with original model, optimized structure increased front portion energy $(2.97 \%)$ and total energy absorption $(2.84 \%)$, without significant difference. The front energy absorption percentage was increased to $51.1 \%$, which can meet the industry requirement. It was illustrated that the optimization was effective.

B column acceleration fluctuation range was reduced, as shown in Fig. (7). And the peak value time was move backwards, and the value reduced by $10.1 \%$, which illustrated the improved performance on acceleration response during impact.

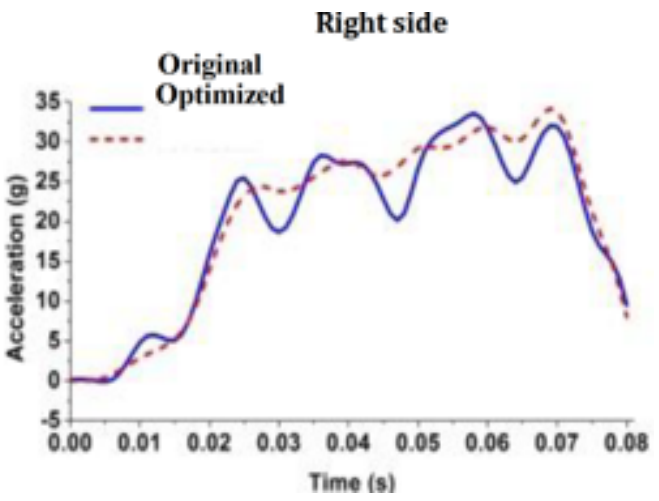


Table 4. Energy absorption value and range.

\begin{tabular}{|c|c|c|c|c|}
\hline Level & A & B & C & D \\
\hline \hline $\mathrm{K}_{1}$ & 67290.5 & 66912.0 & 67496.3 & 68654.1 \\
\hline $\mathrm{K}_{2}$ & 68004.8 & 67400.9 & 68247.2 & 67632.7 \\
\hline $\mathrm{K}_{3}$ & 68077.3 & 69059.7 & 67629.1 & 67085.8 \\
\hline $\mathrm{R}$ & 786.79 & 2147.69 & 750.92 & 1568.38 \\
\hline
\end{tabular}

Table 5. B column acceleration peak value and range.

\begin{tabular}{|c|c|c|c|c|}
\hline Level & A & B & C & D \\
\hline \hline $\mathrm{K}_{1}$ & 32.27 & 32.83 & 32.17 & 32.97 \\
\hline $\mathrm{K}_{2}$ & 32.66 & 32.12 & 33.03 & 31.63 \\
\hline $\mathrm{K}_{3}$ & 32.07 & 32.06 & 31.80 & 32.40 \\
\hline $\mathrm{R}$ & 0.59 & 0.76 & 1.23 & 1.33 \\
\hline
\end{tabular}

Table 6. Energy absorption before and after optimizing.

\begin{tabular}{|c|c|c|c|}
\hline & Front $/ \mathbf{J}$ & Total/J & Percent/\% \\
\hline \hline Original & 68826.12 & 138260 & 49.8 \\
\hline Optimized & 70871.73 & 138653 & 51.1 \\
\hline
\end{tabular}

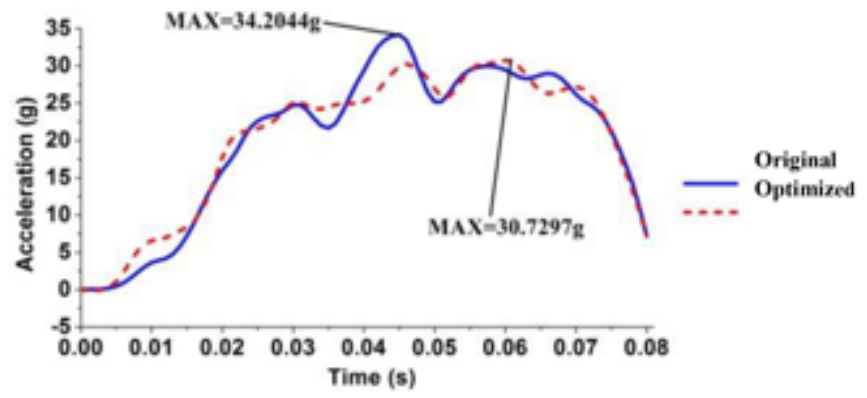

Fig. (7). B column acceleration for original and optimized models.

\section{CONCLUSION}

In this paper, the vehicle front structure energy absorption performance was studied, and orthogonal optimization was implemented to improve structure energy absorbing.

Simulation results indicated that modification was needed for the original structure to meet the industry requirements. Based on simplified whole vehicle model, orthogonal design optimization was implemented, including bumper cross beam material (A), bumper cross beam thickness (B), energy absorber groove distance (C), and front longitudinal beam groove number (D). The best option was
B3D1A3C3 which was gained by using range analysis and integrated balance method. Simulation results showed that both front and total energy absorptions were improved. The optimized structure increased front energy absorption by to $51.1 \%$, which can meet the industry requirement.

\section{CONFLICT OF INTEREST}

The authors confirm that this article content has no conflict of interest.

\section{ACKNOWLEDGEMENTS}

The research was funded by the $12^{\text {th }}$ Five-year Support Program in Shanghai University of Engineering Science (nhky-2012-09), and the Shanghai Education Committee Innovation Program (13YZ109).

\section{REFERENCES}

[1] J.H. Zhang, H.L. Du, and C.S. Ma, Automotive Design for Crash Safety, Beijing, Tsinghua University Press, 2000.

[2] Z.H. Zhong, W.G. Zhang, L.B. Cao, W. He. "Automotive Crash Safety Technology", Beijing, China Machine Press, 2003.

[3] Q.B. Deng, "Research on the Simulation and Reconstruction of Vehicle Collision Based on Energy Absorption Analyses," Master Thesis, Harbin Institut. Technol., Harbin, China, 2010.

[4] P. Lorenzo, "Comparison of the energy absorption capability of crash boxed assembled by spot-weld and continuous joining techniques", Int. J. Impact Eng., pp. 498-511, 2009.

[5] E. Emil, "Comparison of deformation properties of steel sheets for car body parts", Proc. Eng., pp. 115-122, 2012.

[6] O. Jovan, "Lightweight design and crash analysis of composite frontal impact energy absorbing structures", Composite Struct., vol. 94, pp. 423-430, 2012.

[7] W.G. Zhang, X.T. Liao, and Z.H. Zhong, "Multi-objective optimization for crash safety design of vehicles using stepwise regression model", Chin. J. Mech. Eng., vol. 43, no. 8, pp. 142-147, 2007.

[8] G.C. Wang, A.G. Cheng, H. Gao, Z. H. Zhong. "A Study on the effects of strain rate on the crashworthiness of vehicle", Automot. Eng., vol. 32, no. 6, pp. 482-485, 2010.

[9] X.S. Cheng, W.H. Liu, Y.M. Hao, Z.L. Ma, H.B. Tang. "Optimization of a Passenger car's bumper beam for crashworthiness", Automot. Technol., no. 10, pp. 5-9, 2011.

[10] Y.J. Zhou, F.C. Lan, X.M. Wei, C.M. Wu. "A study on the matching law of high strength steel sheets for car-body front-end structures based on frontal impact requirements", Automot. Technol., vol. 31, no. 10, pp. 990-994, 2009.

[11] L.J. Wang, H. Chen, X.H. Qiang, H.N. Chen. "Effects of crash trigger on behavior of thin-walled straight beam in frontal impact", J. Appl. Sci., vol. 13, no. 22, pp. 5210-5214, 2013. 
[12] Regulation from China-New Car Assessment Program, http://www. c-ncap.org. 2012

Received: January 8, 2015

Revised: January 15, 2015
L. J. Wang, Research on Vehicle Frontal Impact and Anti-Collision Structure Energy Absorption, Master thesis, Shanghai University of Engineering Science, Shanghai, China, 2014.

\section{(C) Chen et al.; Licensee Bentham Open.}

This is an open access article licensed under the terms of the Creative Commons Attribution Non-Commercial License (http://creativecommons.org/licenses/by-nc/4.0/) which permits unrestricted, non-commercial use, distribution and reproduction in any medium, provided the work is properly cited. 